\title{
Review of a 10-year experience of rigid bronchoscopy at a tertiary centre in Singapore
}

\author{
Akash Verma ${ }^{1}$, Dessmon Y. H. Tai ${ }^{1}$, Soon Keng Goh ${ }^{1}$, Rajiv Goyal ${ }^{2}$, Ai Ching Kor ${ }^{1}$, \\ Alan W. K. $\mathrm{Ng}^{1}$
}

${ }^{1}$ Department of Respiratory and Critical Care Medicine, Tan Tock Seng Hospital, Singapore

${ }^{2}$ Department of Respiratory and Critical Care Medicine, Jaipur Golden Hospital, Delhi, India

Received: February 10, 2020

Revised: June 2, 2020

Accepted: June 3, 2020

Corresponding author:

Akash Verma

Department of Respiratory and

Critical Care Medicine, Tan Tock

Seng Hospital, 11 Jalan Tan Tock

Seng, 308433, Singapore

Tel: $+65-63573790$

E-mail:

akashverma100@hotmail.com

\section{ABSTRACT}

Purpose: No report of rigid bronchoscopy (RB) has been described from Singapore. Methods: We did a retrospective review of medical records of patients undergoing RB between November 2009 and November 2019 at Tan Tock Seng Hospital.

Results: 135 patients underwent 203 RB. RB was done for malignant central airway obstruction (MCAO) in 91 and benign diseases in 44 patients. The techniques used were Nd: YAG laser $(n=56)$, stenting $(n=63)$, transbronchial needle aspiration $(n=5)$, clot removal $(n=9)$, ballooning $(n=15)$, argon plasma coagulation $(n=5)$, and electrocautery $(n=37)$. Procedural complications occurred in three (2.2\%). Median survival was 10.1 months (interquartile range [IQR], 2.2 to 45.3) in the whole group, 7.8 (IQR, 2 to 18.3 ) in MCAO and 42.6 (IQR, 8.9 to 77.5) in benign diseases respectively. Twenty-two (16.3\%) patients requiring intensive care unit survived for 7.1 months (IQR, 1.6 to 9.8) after RB. Twenty-eight (21\%) patients required repeat RB 68 times. Of these $34(50 \%)$ were for granulation tissue removal.

Conclusion: RB was safe and improved survival however, the demand was low. The most common indications were re-canalization of MCAO and granulation tissue removal. The later was the most resource consuming indication for repeat RB. Future research should focus on minimization of granulation tissue formation.

Keywords: Bronchoscopy; Central airway obstruction; Lasers; Lung neoplasms; Stents

\section{INTRODUCTION}

From a clinical standpoint, the value of rigid bronchoscopy (RB) in prolonging survival in patients with malignant central airway obstruction (MCAO) has been well established [1-3]. As the median survival in patients with untreated advanced lung cancer is only 6 months, re-canalizing their airway, and giving them a chance to undergo cancer target therapy prolongs their survival identical to those who do not have MCAO and are able to undergo chemotherapy without difficulty $[2,4]$. Its role as an alternative to surgery in establishing airway patency in benign diseases such as TB stricture and post-intubation tracheal stenosis (PITS) is also adequately de-
This is an Open Access article distributed under the terms of the Creative Commons Attribution Non-Commercial License (https:// creativecommons.org/licenses/ by-nc/4.0/). 
scribed [5,6].

Those who present with respiratory failure (RF) requiring intensive care unit (ICU) from MCAO or benign disease are hardest to manage. It is challenging to administer radiotherapy or chemotherapy to intubated patients in the ICU. Lack of RB in such situations predisposes them to remain dependent on mechanical ventilation (MV) for prolonged period and eventually succumb to its complications resulting in a very short survival. However, RB, by enabling liberation from MV, allows survival benefit to ensue from chemoradiotherapy by enabling them to undergo it [7].

From an economic standpoint, RB has been described to show the potential for economic benefit for ICU patients [8]. Several patients are admitted to ICU for RF from MCAO. Lack of RB would predispose them to failure to wean from MV for prolonged period lengthening the ICU length of stay (ICULOS). RB however allows sparing ICU beds by de-escalation of care in such patients thus conferring economic benefit [7]. As a result, training in RB has picked up in recent years. We did the present study to review the overall demand, dominant indications, commonly required techniques, survival benefit, and potential for any economic benefit from RB done over a 10-year period at our centre.

\section{METHODS}

We retrospectively reviewed patients undergoing RB between November 2009 and November 2019 at Tan Tock Seng Hospital. Variables such as demographic data, indication of $\mathrm{RB}$, types of endoscopic techniques, sites of intervention, effect of intervention on luminal patency, radiological effect of intervention, effect on change in level of care, survival, and complications were collected.

$\mathrm{RB}$ was performed in the operating room. A rigid bronchoscope either BRONCHOSCOPE EFER-DUMON ${ }^{\mathrm{TM}}$ (EFER Endoscopy, La Ciotat, France) or KARL STORZ Endoscopy-America, Inc. (El Segundo, CA, USA) was inserted in the airway under general anaesthesia. Patients were ventilated using an automated jet ventilator. Rigid telescope, flexible bronchoscope, and other instruments were inserted through the primary lumen of the rigid bronchoscope. Airway dilation was performed with controlled radial expansion pulmonary balloon dilators (Boston Scientific, Natick, MA, USA). Tumour debridement was performed with flexible or rigid forceps or by coring out with the barrel of the rigid bronchoscope. Nd: YAG laser, and argon plasma coagulation (APC; ERBE USA Inc., Marietta, GA, USA), and Electrocautery were used as pre- ferred heat modalities for tumour ablation, granulation tissue removal, or haemostasis. The metal stents used were UItraflex (Boston Scientific), and silicone stents were NOVATECH Dumon stents (Boston Medical Products Inc., Westborough, MA, USA).

Blood clots causing central airway obstruction were extracted with rigid forceps and/or suction through the barrel of the RB.

In general, intraluminal malignant lesions were debrided after using heat modalities for tumour ablation and haemostasis. Extra-luminal lesions causing compression of the airway were stented. Debridement with stent placement was performed for mixed lesions. Silicone stents were used preferentially for the benign lesions. Covered metal stents were used for malignant lesions. Routine treatment including chemotherapy and radiation were provided to the patients under the supervision of their oncologists. Patients with benign central airway obstruction also underwent routine therapy for the underlying condition. All procedures were performed by two experienced interventional pulmonologists-AWKN (from 2009 to 2019) and AV (2014 to 2019). Approval was obtained from the Institutional Review Board of National Health Care Group to review and publish patient records retrospectively (IRB No. 2017/01019). Informed consent was waived because of the retrospective nature of the study.

\section{RESULTS}

One hundred thirty-five 135 patients underwent 203 RB over a 10-year period. Median age was 63 (interquartile range [IQR], 51 to 73 ). Seventy-six (56.2\%) were males; 22 (16.3\%) patients were in the ICU at the time RB and three (2.2\%) had tracheostomy.

Ninety-one patients underwent RB for MCAO and 44 for benign diseases (Tables 1, 2). Among patients with MCAO, squamous cell carcinoma 17 (18.7\%), adenocarcinoma lung 15 (16.5\%), and oesophageal carcinoma $14(15.3 \%)$ were the most common malignancies (Fig. 1). Among patients with benign diseases, TB stricture $14(31.8 \%)$ and blood clot in the airways nine (20.5\%) were the most common conditions (Fig. 1).

The techniques used via RB were Nd: YAG laser $(n=56)$, stenting $(n=63)$, transbronchial needle aspiration $(n=5)$, clot removal $(n=9)$, ballooning $(n=5), \operatorname{APC}(n=5)$, and electrocautery $(n=37)$ in six of which, snare was used (Table 3$)$.

Sixty-three patients had 72 stents placed. Metal stent was the most commonly placed stent in 50 (79.4\%) patients. 
Table 1. Malignant diseases requiring rigid bronchoscopy $(n=91)$

\begin{tabular}{|c|c|}
\hline Malignant disease & No. (\%) \\
\hline \multicolumn{2}{|l|}{ Primary lung cancer } \\
\hline \multicolumn{2}{|l|}{ Non-small cell carcinoma } \\
\hline Squamous cell carcinoma lung & $17(18.7)$ \\
\hline Adenocarcinoma lung & $15(16.5)$ \\
\hline Large cell carcinoma lung & $1(1.1)$ \\
\hline Small cell carcinoma lung & $5(5.5)$ \\
\hline Poorly differentiated carcinoma lung & $2(2.1)$ \\
\hline Neuroendocrine carcinoma lung & $2(2.1)$ \\
\hline Adenoid cystic carcinoma & $4(4.3)$ \\
\hline Mucoepidermoid carcinoma & $2(2.1)$ \\
\hline Carcinoid & $2(2.1)$ \\
\hline Granular cell tumor & $2(2.1)$ \\
\hline \multicolumn{2}{|l|}{ Metastatic cancer } \\
\hline Breast carcinoma & $1(1.1)$ \\
\hline Renal cell carcinoma & $3(3.3)$ \\
\hline Thyroid carcinoma & $2(2.1)$ \\
\hline Esophageal carcinoma & $14(15.4)$ \\
\hline Colorectal carcinoma & $1(1.1)$ \\
\hline Gastric carcinoma & $1(1.1)$ \\
\hline Glomus tumor & $1(1.1)$ \\
\hline Nasopharyngeal carcinoma & $1(1.1)$ \\
\hline Sarcomatoid carcinoma & $1(1.1)$ \\
\hline Leiomyoma & $1(1.1)$ \\
\hline Lymphoepithelioma-like lung carcinoma & $1(1.1)$ \\
\hline MALT lymphoma & $1(1.1)$ \\
\hline Epstein Barr virus related neoplasm & $1(1.1)$ \\
\hline Other carcinoma & $10(11)$ \\
\hline Total & $91(100)$ \\
\hline
\end{tabular}

MALT, mucosa associated lymphoid tissue.

Among 50 patients with MCAO, $45(90 \%)$ had metal stent placed. Thirteen had benign disease of whom five (38.5\%) had metal stent placed. Median stent in-dwelling time was 6.4 months (IQR, 1.7 to 14). In-dwelling time for MCAO and benign disease was 5 months (IQR, 1.2 to 9.8) versus 82.3 months (IQR, 5.7 to 101.7 ) respectively. Longest indwelling time for the metal and silicone stent was 4.8 years in a patient with oesophageal cancer and 11.4 years in patient with amyloidosis respectively (Table 3 ).

Two (1.4\%) patients experienced coughing out stent, two (1.4\%) fracture, five (3.7\%) migration, and eight (6\%) granulation tissue formation. In stented MCAO group, 3/50 (6\%)
Table 2. Benign diseases requiring rigid bronchoscopy $(n=44)$

\begin{tabular}{lc}
\hline Benign disease & No. (\%) \\
\hline Post tuberculosis stricture & $14(31.8)$ \\
Blood clot removal & $9(20.5)$ \\
Post-intubation tracheal stenosis & $4(9.1)$ \\
Foreign body removal & $4(9.1)$ \\
Acute on chronic inflammation & $3(6.8)$ \\
Tubercular lymphadenitis & $2(4.5)$ \\
Goitre & $2(4.5)$ \\
Broncholith & $1(2.3)$ \\
Pneumonia & $1(2.3)$ \\
Bronchogenic cyst & $1(2.3)$ \\
Tracheal amyloidosis & $1(2.3)$ \\
Unknown & $3(6.8)$ \\
Total & $44(100)$ \\
\hline
\end{tabular}

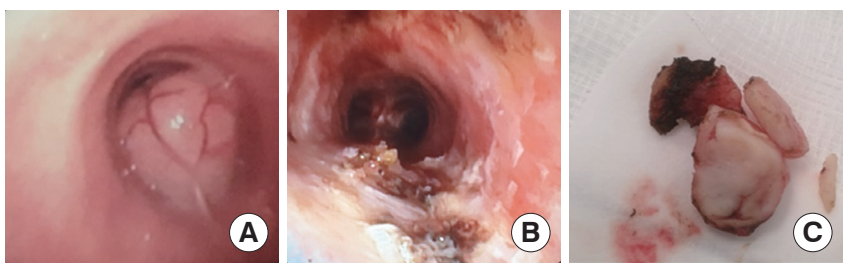

Fig. 1. (A) A 32-year-old female presented with stridor and loss of voice. The bronchoscopy revealed a polypoidal lesion causing near complete occlusion of the mid trachea. (B) This was removed with electrocautery snare. (C) Removed tumour. Histology showed leiomyoma.

survived $>2$ years, and in stented benign diseases group, 8/ $13(61.5 \%)$ survived $>2$ years (up to 6 years), and $2 / 13(15.3 \%)$ survived $>9$ years. Although metal stent is contraindicated in benign diseases, it was placed in $5 / 13(38.4 \%)$ of such patents.

Median survival was 10.1 months (IQR, 2.2 to 45.3 ) in the whole group. Survival in MCAO and benign disease was 7.8 months (IQR, 2 to 18.3 ) versus 42.6 months (IQR, 8.9 to 77.5 ) respectively. In the poorest prognosis group of 22 patients (those having RF from advanced cancer requiring MV) survived for the period of 7.1 months (IQR, 1.6 to 9.8). In addition, level of care could be de-escalated to general ward soon after the RB in these patients. Patients with advanced lung cancer without RF survived for 9.2 months (IQR, 4.1 to 16.9)2 months longer than the anticipated survival associated with untreated advanced lung cancer.

Out of 135, 28 (21\%) patients required repeat RB 68 times (Table 4). Thirty-four (50\%) of these repeat RB were for granulation tissue removal in eight patients, 10 (14.7\%) were for 
Table 3. Rigid bronchoscopy techniques and outcomes $(n=135)$

\begin{tabular}{|c|c|}
\hline Variable & Value \\
\hline \multicolumn{2}{|l|}{ Resource utilization $(n=135)$} \\
\hline Number of rigid bronchoscopies & 203 \\
\hline $\begin{array}{l}\text { Rigid bronchoscopies per patient in the whole } \\
\text { group }\end{array}$ & 1.5 \\
\hline Patients requiring repeat $(>1) \mathrm{RB}$ & $28(21)$ \\
\hline $\begin{array}{l}\text { Rigid bronchoscopies per patient in the repeat } \\
\text { group }\end{array}$ & 2.4 \\
\hline \multicolumn{2}{|l|}{ Techniques $(n=203)$} \\
\hline Balloon dilatation (sessions) & $15(7.4)$ \\
\hline Nd:YAG (sessions) & $56(27.6)$ \\
\hline Stenting (number of patients) & $63(31)$ \\
\hline Electrocautery (sessions) & $37(18.2)$ \\
\hline Argon plasma coagulation & $5(2.5)$ \\
\hline Airway clot extraction & $9(4.4)$ \\
\hline Transbronchial needle aspiration & $5(2.5)$ \\
\hline Mechanical dilatation & $3(1.5)$ \\
\hline Stent removal & $10(4.9)$ \\
\hline \multicolumn{2}{|l|}{ Patients requiring stent $(n=63)$} \\
\hline Number of stents placed & 72 \\
\hline Silicone stent & 22 \\
\hline Ultraflex covered metal stent & 50 \\
\hline Stent indwelling time (mo) & $6.4(1.7-14)$ \\
\hline Stent indwelling time (MCAO) (mo) & $5(1.2-9.8)$ \\
\hline Stent indwelling time (BCAO) (mo) & $82.3(5.7-101.7)$ \\
\hline Longest indwelling time for the metal stent (mo) & 57.6 \\
\hline Longest indwelling time for the silicone stent (mo) & 136.8 \\
\hline \multicolumn{2}{|l|}{ Survival $(n=135)$} \\
\hline Whole group (mo) & $10.1(2.2-45.3)$ \\
\hline Malignant central airway obstruction & $7.8(2-18.3)$ \\
\hline Benign central airway obstruction & $42.6(8.9-77.5)$ \\
\hline $\begin{array}{l}\text { Patients with advanced lung cancer with RF } \\
\text { requiring MV }\end{array}$ & $7.1(1.6-9.8)$ \\
\hline \multicolumn{2}{|l|}{ ICU patients $(n=22)$} \\
\hline Patients in ICU & $22(16.3)$ \\
\hline Prompt successful extubation & $12(54.5)$ \\
\hline ICU length of stay (day) & $11.5(1-70)$ \\
\hline Post-intervention ICU length of stay (day) & $3(1-60)$ \\
\hline
\end{tabular}

Values are presented as number (\%) or median (interquartile range). $\mathrm{RB}$, rigid bronchoscopy; MCAO, malignant central airway obstruction; $\mathrm{BCAO}$, benign central airway obstruction; RF, respiratory failure; $\mathrm{MV}$, mechanical ventilation; ICU, intensive care unit.
Table 4. The burden of repeat (>1 in single patient) rigid bronchoscopy $(n=28)$

\begin{tabular}{lcc}
\hline Variable & $\begin{array}{c}\text { Bronchoscopy } \\
(\mathrm{n}=68)\end{array}$ & $\begin{array}{c}\text { Patients } \\
(\mathrm{n}=28)\end{array}$ \\
\hline Granulation tissue removal & $34(50)$ & $8(5.9)$ \\
Stent insertion & $23(33.8)$ & $21(75)$ \\
Balloon dilatation & $10(14.7)$ & $7(25)$ \\
Laser resection of tumor or web & $16(23.5)$ & $5(17.8)$ \\
Stent removal & $10(14.7)$ & $9(32.1)$ \\
\hline
\end{tabular}

Values are presented as number (\%).
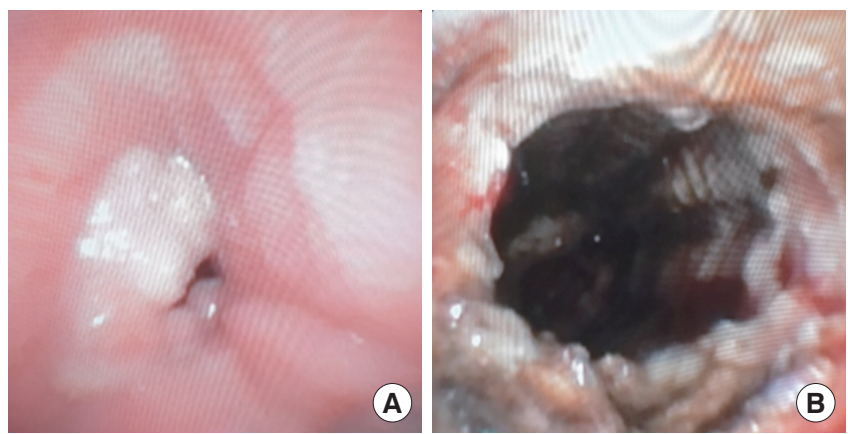

Fig. 2. (A) A 60-year-old female with adenoid cystic carcinoma in the mid trachea requiring Ultraflex covered metal stent for recanalization. She developed granulation tissue over the proximal end of the stent causing stridor. (B) The granulation tissue was removed using argon plasma coagulation and electrocautery with good result.

stent removal, 23 (33.8\%) for stent insertion, 10 (14.7\%) for ballooning, and 16 (23.5\%) for tumour or web resection. Most frequent indication for repeating the RB was granulation tissue removal making it the most resource consuming condition for a small proportion $6 \%$ of patients (Table 4). The median interval between stent placement and granulation tissue formation requiring intervention was 13.3 months (IQR, 5.4 to 19.4). In two patients with Ultraflex metal stent in the trachea, the interval between stent placement and granulation tissue formation was 402, and 461 days respectively. Electrocautery was the most commonly used modality for managing the granulation tissue formation (Fig. 2). Thirty-five (26\%) patients underwent inspection flexible bronchoscopy within median of 4 days (IQR, 2.5 to 8.5 ) prior to RB.

Procedural complications occurred in three $(2.2 \%)$ patients (Table 5). One (0.7\%) sustained hypoxic encephalopathy (HIE) from pulse less electrical activity (PEA) due to excessive bleeding from laser resection and one had stroke (0.7\%). Unexpected RF within 24 hours was seen in two (1.5\%) patients. Fifteen (11.1\%) patients died within 30 days of intervention. 
Table 5. Procedural complications $(n=135)$

\begin{tabular}{|c|c|c|c|}
\hline Variable & Total $(n=135)$ & Malignant $(n=91)$ & Benign $(n=44)$ \\
\hline Procedural complications & $3(2.2)$ & $3(3.3)$ & - \\
\hline Cardiac arrest requiring CPR & $1(0.7)$ & $1(1.1)$ & - \\
\hline PEA collapse from massive haemorrhage complicated by HIE & $1(0.7)$ & $1(1.1)$ & - \\
\hline Right hemiparesis & $1(0.7)$ & $1(1.1)$ & - \\
\hline Transferred to intensive care unit post-procedure & $6(4.4)$ & $4(4.4)$ & $2(4.5)$ \\
\hline 30-Day mortality & $15(11.1)$ & $10(11)$ & $5(11.3)$ \\
\hline Unexpected respiratory failure in 24 hours & $2(1.5)$ & $2(2.2)$ & \\
\hline
\end{tabular}

Values are presented as number (\%).

$\mathrm{CPR}$, cardiopulmonary resuscitation; PEA, pulse less electrical activity; HIE, hypoxic ischemic encephalopathy.

Six (4.4\%) patients required transfer to ICU after the RB for stabilization and overnight monitoring.

\section{DISCUSSION}

The demand of RB was 1.1 patients per month. RB carried survival benefit and potential for economic benefit with a low complication rate. First RB prompted repeat sessions in $21 \%$ patients. Granulation tissue formation after stent placement was the most common, most detrimental, and most resource consuming reason for requiring repeat $\mathrm{RB}$.

The demand of RB was low. Since RB is performed at three large tertiary centres in Singapore, the approximate national demand can be extrapolated to 3.3 patients per month over the population of 5.5 million. To find how this compares with other regions, we found lack of studies reporting the national demand of RB. When we tried to glean information by extrapolation of the data from the existing literature, we could deduce this demand approximately. For example, in South Korea, a demand of 2.6 patients per month can be derived based on the reported 307 patients undergoing RB over 10 year period in Samsung Medical Centre, one of the five largest tertiary hospitals in South Korea [9-12]. If extrapolated to all five largest tertiary hospitals in Korea (The Big-5), the national demand can be derived to be 12.7 patients per month over the population of 51 million, which is consistent with our demand [13].

Correspondingly, the AQuIRE registry from USA reported 733 RB done over 5-year period from 15 centres in 11 states in USA suggesting the national demand of 12.2 per month over the population of 111 million, which is lower than our demand [14]. Investigators from East Malaysia with a population of 5 million reported 90 patients requiring RB over 1 year suggesting the demand of 7.5 patients per month, which was higher than our demand [15]. Based on these data, the demand for RB can be summarised as 1.3 to 3 patients per month per 2 million.

This carries implications for training. Learning a technique with potential risks, with low volume of patients not only makes acquiring the skill difficult, it also makes it difficult to maintain the competency. This may warrant modulation for recruitment into national $\mathrm{RB}$ training programs so as to match the national volume with the number of training positions in a way that sufficient work load exists per interventional pulmonologist to maintain competency.

Malignant disease was the indication for performing RB in more than half of the patients in keeping with previous reports. This suggests greater demand for RB for malignant diseases than benign $[16,17]$. This is due to the lower incidence of PITS or post-TB strictures compared to primary lung malignancy or metastasis from extra pulmonary malignancy to lung. Even where the incidence of endobronchial tuberculosis (TB) is reported as high as $50 \%$ in regions with high incidence of TB, the number of patients who develop strictures requiring re-canalization are low [18]. However, one study of 126 patients undergoing RB for re-canalization from Thailand reported modestly higher number (41.3\%) of patients with TB strictures than malignancy (35.7\%) [19].

Among malignant diseases requiring $\mathrm{RB}$, adenocarcinoma lung affected the central airways as much as the squamous cell carcinoma in our cohort [20-22]. Since the survival has improved dramatically in adenocarcinoma by virtue of tyrosine-kinase inhibitors (TKI's), approach to MCAO should become even less nihilistic than ever to tide patients over the RF from central airway obstruction to enable them for good survival downstream. In our study squamous cell carcinoma 
lung, adenocarcinoma lung, and squamous cell carcinoma of the oesophagus were the commonest histological subtypes requiring $\mathrm{RB}$ in keeping with previous reports $[2,16,17,23]$.

Among benign diseases requiring RB, post-TB stricture and blood clots were most commonly encountered conditions. This highlights the importance of maintaining skills of radial laser resection, silicone stent placement, and cryo-therapy. TB strictures often present as circumferential membrane-like narrowing at multiples sites. This requires either radial resection with the laser, or silicone stent placement by virtue of unfeasibility of surgical resection and anastomosis. Patients with blood clots on the other hand pose a different challenge. They frequently cause cardiac arrest from them and are too soft to be removed by grasping with the biopsy forceps. They are best removed by cryo-adherence to the cryoprobe highlighting the importance of this service (we do not have cryo-therapy at our centre and therefore had to resort to RB for clot extraction in nine patients) [24].

Almost half the patients had stent placed in our cohort. Metal stents are contraindicated in benign airway diseases [25]. However, they were placed in close to $40 \%$ of such patients in our cohort and were tolerated well as reported by other authors and remained in situ for prolonged periods of time without any significant complications [26-29]. Longest indwelling time for the metal and silicone stent was 4.8 years in a patient with oesophageal cancer and 11.4 years in a patient with tracheal amyloidosis respectively.

Multiple RB was required in $1 / 5$ th of the patients. It is noteworthy that half of the repeat RB were paradoxically performed on minority of patients $(n=8)$ for the purpose of granulation tissue removal, making it the most resource consuming condition.

Incidence of granulation tissue formation after stent ranges from $0.9 \%$ to $14.6 \%[23,26,30,31]$. In a study by Chung et al. [27], the granulation tissue formation was seen in $15.2 \%$ of patients after uncovered self-expanding metal stent (SEMS) insertion. In a study of 47 patients by Abdel-Rahman et al. [29], granulation tissue requiring treatment was seen in $65 \%$ of patients with uncovered SEMS with the indwelling time of 30 months (IQR, 16 to 48). Lower rate of granulation tissue formation in our cohort could be due to the use of silicone or "covered" SEMS in our cohort compared to the use of "uncovered" SEMS in the above two studies.

The median interval between stent placement and granulation tissue formation requiring intervention was 13.3 months (IQR, 5.4 to 19.4) in our cohort. In a study by Chung et al. [27], time to develop granulation tissue was shorter-
2.6 months (IQR, 1.1 to 12.6) than our cohort likely due to use of uncovered SEMS [27]. Knowing the time taken to form granulation tissue is important as it can be used as a yard stick to anticipate onset of airway compromise and plan bronchoscopic intervention electively.

With regards to its management, it was the most resource consuming indication as well as most detrimental as patients often presented with breathing difficulty due to compromise of the airway lumen from it. For the purpose of this study, only the granulation tissue removal performed via RB was included in the analysis excluding those in whom FB was used to remove granulation tissue. However, if included, the granulation tissue would turn out to be even more resource consuming than the current description. Thirty-four RB and 62 FB required in eight patients (12 bronchosocpies per patient) were for granulation tissue removal only, implying granulation tissue formation to be an expensive condition indicating need for research on how to minimize it. Electrocautery with or without APC proved to be an effective modality for managing it, in keeping with the report by Chung et al. [27].

RB provided survival benefit. This was most apparent in the ICU patients who were liberated from MV and discharged from ICU to go onto receive cancer targeted therapy as a result of RB. Although MV was effective in splinting open their obstructed airways, it would eventually predispose them to succumb to the complications of prolonged MV. Such patients survived for median of 7.1 months, with maximum of 5 years. Survival benefit was also conceivable in patients having central airway obstruction without RF. As the median survival in patients with untreated advanced lung cancer is only 6 months, re-canalizing their airway, allowed them to undergo cancer target therapy which is known to carry median survival of 1 year and 2 years with chemotherapy and TKl's respectively [32].

Regarding economic benefit, a quarter of patients underwent inspection flexible bronchoscopy within 4 days prior to RB. Since each bronchoscopy costs approximately 1,000 Singapore dollars, this amounts to 35,000 over 10 years amortised to 3,500 per year. If RB is undertaken directly, it may confer economic benefit by saving this cost. Second, it is known that ventilator days attributable to prolonged intubation contribute to cost in the ICU patients. It is also described that patients who get operated upon have lesser ICU-LOS compared to those who don't [33]. RB is known to de-escalate the level of care to general ward by facilitating prompt liberation from MV and discharge from ICU thus carrying potential for economic benefit. In terms of safety, RB was a safe 
procedure with the complication rate of $2.2 \%$.

Being from a single centre and of retrospective nature, our study has limitations. In addition, the data on date of death was not available on some patients to allow accurate assessment of survival. The average was used to key in the place of missing data for analysis. Second, the extrapolation of the national demand of RB from the existing literature in various regions is arguably not an accurate method of identifying such demand. However, authors believe that the combination of the absence of national registries, scarcity of published data from each and every centre, and the well known fact of few indications for RB, it is reasonable to accept the low demand of this procedure to highlight the important point of its implications on training. The strength of our study is that it is a first report of long term experience of RB from Singapore to describe the perspective on clinical and economic benefit of RB on one hand, and potential implications on training on the other.

In conclusion, following insights can be gained from our study: (1) RB is a safe, and 'survival prolonging' procedure. (2) Although varies geographically, the most common indications for RB are re-canalization of MCAO and granulation tissue removal. (3) Granulation tissue develops approximately 1-year post-stenting and Electrocautery with or without APC is effective in its management. It is the most resource consuming complication of placing the stent in the airways. (4) In ICU patients, RB may confer economic benefit by de-escalation of care. Further economic benefit could be gleaned from RB by avoiding inspection FB prior to RB and finding ways to minimize granulation tissue formation. Further studies should focus on these factors. (5) Low demand for RB may warrant policy makers and program directors of RB training programs to consider matching the enrolment into the program with national demand to ensure maintenance of competency.

\section{CONFLICTS OF INTEREST}

No potential conflict of interest relevant to this article was reported.

\section{ORCID}

Akash Verma https://orcid.org/0000-0002-7000-8708

Dessmon Y.H. Tai https://orcid.org/0000-0002-8597-8811

Soon Keng Goh https://orcid.org/0000-0002-0245-6752

Rajiv Goyal https://orcid.org/0000-0002-2589-8342
Ai Ching Kor https://orcid.org/0000-0003-3582-7254

Alan W.K. Ng https://orcid.org/0000-0002-0446-0261

\section{AUTHOR CONTRIBUTIONS}

Conception or design: AV, RG, AWKN.

Acquisition, analysis, or interpretation of data: AV, DYHT.

Drafting the work or revising: AV, DYHT, SKG, RG, ACK.

Final approval of the manuscript: RG, AWKN.

\section{REFERENCES}

1. Ginsberg RJ, Vokes EE, Ruben A. Non-small cell lung cancer. In: DeVita VT Jr, Hellman S, Rosenberg SA, editors. Cancer: principles and practice of oncology. 5 th ed. Philadelphia (PA): Lippincott-Raven; 1997. p. 858-911.

2. Chhajed PN, Baty F, Pless M, Somandin S, Tamm M, Brutsche $\mathrm{MH}$. Outcome of treated advanced non-small cell lung cancer with and without central airway obstruction. Chest 2006;130:1803-7.

3. Dutau H, Vandemoortele T, Breen DP. Rigid bronchoscopy. Clin Chest Med 2013;34:427-35.

4. Verma A, Goh SK, Tai DYH, Kor AC, Soo Cl, Seow DGF, et al. Outcome of advanced lung cancer with central airway obstruction versus without central airway obstruction. ERJ Open Res 2018;4:00173-2017.

5. Freitag L, Darwiche K. Endoscopic treatment of tracheal stenosis. Thorac Surg Clin 2014;24:27-40.

6. Verma A, Um SW, Koh WJ, Suh GY, Chung MP, Kwon OJ, et al. Long-term tolerance of airway silicone stent in patients with post-tuberculosis tracheobronchial stenosis. ASAIO J 2012;58:530-4.

7. Verma A, Sim WY, Tai DY, Goh SK, Kor AC, Phua CK, et al. Role of bronchoscopy in prompt discharge from the intensive care unit. J Bronchology Interv Pulmonol 2016; 23:123-30.

8. Murgu S, Langer S, Colt H. Bronchoscopic intervention obviates the need for continued mechanical ventilation in patients with airway obstruction and respiratory failure from inoperable non-small-cell lung cancer. Respiration 2012;84:55-61.

9. Shin B, Chang B, Kim H, Jeong BH. Interventional bronchoscopy in malignant central airway obstruction by extra-pulmonary malignancy. BMC Pulm Med 2018;18:46.

10. Jeong BH, Um SW, Suh GY, Chung MP, Kwon OJ, Kim H, et al. Results of interventional bronchoscopy in the management of postoperative tracheobronchial stenosis. J 
Thorac Cardiovasc Surg 2012;144:217-22.

11. Eom JS, Kim H, Park HY, Jeon K, Um SW, Koh WJ, et al. Timing of silicone stent removal in patients with post-tuberculosis bronchial stenosis. Ann Thorac Med 2013;8:218-23.

12. Park HY, Kim H, Koh WJ, Suh GY, Chung MP, Kwon OJ. Natural stent in the management of post-intubation tracheal stenosis. Respirology 2009;14:583-8.

13. Korea Biomedical Review. Big 5-hospitals dominate patient care, 2018 [Internet]. Seoul (KR): Korea Biomedical Review; c2020 [cited 2020 Jun 10]. Available from: http:// www.koreabiomed.com/news/articleView.html?idxno $=2778$.

14. Ost DE, Ernst A, Grosu HB, Lei X, Diaz-Mendoza J, Slade M, et al. Complications following therapeutic bronchoscopy for malignant central airway obstruction: results of the AQuIRE registry. Chest 2015;148:450-71.

15. Rashid Ali MRS, Sivaraman Kannan KK, Ibrahim A. Rigid bronchoscopy in adult population using total intravenous anaesthesia (TIVA) with spontaneous ventilation in Sabah, East Malaysia. Eur Respir J 2013;42(Suppl 57):P3769.

16. Wood DE, Liu YH, Vallieres E, Karmy-Jones R, Mulligan MS. Airway stenting for malignant and benign tracheobronchial stenosis. Ann Thorac Surg 2003;76:167-72.

17. Jeon K, Kim H, Yu CM, Koh WJ, Suh GY, Chung MP, et al. Rigid bronchoscopic intervention in patients with respiratory failure caused by malignant central airway obstruction. J Thorac Oncol 2006;1:319-23.

18. Jung SS, Park HS, Kim JO, Kim SY. Incidence and clinical predictors of endobronchial tuberculosis in patients with pulmonary tuberculosis. Respirology 2015;20:488-95.

19. Chumpathong S, Tscheikuna J, Boonsombat T, Muangman S, Luansritisakul C. Incidence and risk factors of hypoxemia during interventional rigid bronchoscopy under spontaneous-assisted ventilation. J Bronchology Interv Pulmonol 2017;24:268-74.

20. Kawase A, Yoshida J, Ishii G, Nakao M, Aokage K, Hishida $T$, et al. Differences between squamous cell carcinoma and adenocarcinoma of the lung: are adenocarcinoma and squamous cell carcinoma prognostically equal? Jpn J Clin Oncol 2012;42:189-95.

21. Quinn D, Gianlupi A, Broste S. The changing radiographic presentation of bronchogenic carcinoma with reference to cell types. Chest 1996;110:1474-9.

22. Rosado-de-Christenson ML, Templeton PA, Moran CA. Bronchogenic carcinoma: radiologic-pathologic correla- tion. Radiographics 1994;14:429-46.

23. Cavaliere S, Venuta F, Foccoli P, Toninelli C, La Face B. Endoscopic treatment of malignant airway obstructions in 2,008 patients. Chest 1996;110:1536-42.

24. Lee H, Leem CS, Lee JH, Lee CT, Cho YJ. Successful removal of endobronchial blood clots using bronchoscopic cryotherapy at bedside in the intensive care unit. Tuberc Respir Dis (Seoul) 2014;77:193-6.

25. Schultz D. FDA public health notification: complications from metallic tracheal stents in patients with benign airway disorders [Internet]. Silver Spring (MD): Food and Drug Administration; 2005 [cited 2020 Jun 10]. Available from: www.jsre.org/info/0801_fda.pdf.

26. Saad CP, Murthy S, Krizmanich G, Mehta AC. Self-expandable metallic airway stents and flexible bronchoscopy: long-term outcomes analysis. Chest 2003;124:1993-9.

27. Chung FT, Chen HC, Chou CL, Yu CT, Kuo CH, Kuo HP, et al. An outcome analysis of self-expandable metallic stents in central airway obstruction: a cohort study. J Cardiothorac Surg 2011;6:46.

28. Gottlieb J, Fuehner T, Dierich M, Wiesner O, Simon AR, Welte T. Are metallic stents really safe? A long-term analysis in lung transplant recipients. Eur Respir J 2009;34: 1417-22.

29. Abdel-Rahman N, Kramer MR, Saute M, Raviv Y, Fruchter O. Metallic stents for airway complications after lung transplantation: long-term follow-up. Eur J Cardiothorac Surg 2014;45:854-8.

30. McGrath EE, Warriner D, Anderson P. The insertion of self expanding metal stents with flexible bronchoscopy under sedation for malignant tracheobronchial stenosis: a single-center retrospective analysis. Arch Bronconeumol 2012;48:43-8.

31. Breitenbucher A, Chhajed PN, Brutsche MH, Mordasini C, Schilter D, Tamm M. Long-term follow-up and survival after Ultraflex stent insertion in the management of complex malignant airway stenoses. Respiration 2008;75: 443-9.

32. American College of Chest Physicians. ACCP pulmonary medicine board review. Northbrook (IL): American College of Chest Physicians; 2009. p. 39-62.

33. Toptas M, Sengul Samanci N, Akkoc I, Yucetas E, Cebeci E, Sen $O$, et al. Factors affecting the length of stay in the intensive care unit: our clinical experience. Biomed Res Int 2018;2018:9438046. 